\title{
Influência de diferentes métodos para a realização de preparos cavitários - alta rotação, laser de Er:YAG e abrasão a ar - sobre a resistência de união de um sistema adesivo à dentina* \\ Influence of different devices to shape cavity preparations - handpiece high-speed, Er:YAG laser and air abrasion - on the bond strength of a adhesive system to dentin
}

\author{
Luiz Henrique Burnett Jr. ${ }^{* *}$ \\ Ewerton Nocchi Conceição***
}

\begin{abstract}
RESUMO
O objetivo deste trabalho foi avaliar, in vitro, a resistência de união à tração do sistema adesivo Single Bond (3M) aplicado sobre as superfícies dentinárias tratadas com alta rotação, laser de Er:YAG ou abrasão a ar. Quarenta e cinco amostras de superficies dentinárias foram divididas em três grupos de métodos para realizar preparos cavitários. O grupo com alta rotação recebeu tratamento com uma turbina Roll - Air 3 (Kavo) associada a uma ponta diamantada KG Sorensen $n^{\circ} 3008$ sob refrigeração por 5 segundos. Para o tratamento com laser de Er:YAG foi utilizado um equipamento KavoKey (Kavo) com parâmetros de $450 \mathrm{~mJ}$ e $2 \mathrm{~Hz}$ pelo tempo de 10 segundos para cada corpo de prova. O método de abrasão a ar foi aplicado com um dispositivo Mach 5 (Kreativ) com partículas de óxido de alumínio de $27 \mathrm{~mm}$. Após os tratamentos serem realizados foi aplicado o sistema adesivo Single Bond $(3 \mathrm{M})$ e a resina composta ZI00 (3M) para a confecção dos corpos de prova para o teste de resistência de união à tração. Os resultados obtidos foram: alta rotação (17,52 MPa), laser de Er:YAG (16,65 MPa) e abrasão a ar (15,83 MPa). Após os resultados serem submetidos à análise estatística ANOVA e teste de Tukey $(p<0,01)$ concluiu-se que não houve diferença estatisticamente significativa entre os grupos testados.
\end{abstract}

UNTTERMOS:

Laser, abrasão, dentina, união

\section{INTRODUÇÄO}

Para remover seqüelas da doença cárie, ou seja, o tecido dental cariado é essencial o emprego de um instrumento que permita a realização desta etapa com segurança biológica, conforto ao paciente e profissional, e que ainda possibilite estabelecer os princípios de preparos cavitários específicos para cada material restaurador a ser utilizado nas diferentes situaçöes clínicas. Pierne Fauchard no início do século XVIII, Willman e Schroeder (1897) e G.V.Black apud VINSKI (1979) foram verdadeiros icones da Odontologia ao reportarem respectivamente o desenvolvimento dos instrumentos de corte, brocas de aço-carbono $c$ os princípios básicos dos preparos cavitários. Não obstante, em 1932 DRENDEL apud SIEGEL e VON FRAUNHOFER (1998) desenvolveu um processo de galvanização das particulas abrasivas sobre o aço criando as modernas pontas diamantadas. Desde então, o desenvolvimento de velocidades cada vez maiores propiciou a remoção mais efetiva da estrutura dentária. Todavia, em 1945, BLACK, e desenvolveu o equipamento de abrasāo a ar baseado na propulsão de partículas abrasivas de óxido de alumínio permitindo a remoção da estrutura dentária com menor ruído e sensibilidade dolorosa por parte do paciente. Não obstante, em 1964, STERN e SOGGNAES apud PICK (1993) aplicaram pela primeira vez o uso da luz monocromática, colimada e coerente, o LASER, para realizar a remoção de estrutura dentária. Todavia, as seqüelas de utilização desta luz de elevada energia permitia formação de áreas de carbonização, rachaduras e principalmente o aumento de temperatura acima de $5,5^{\circ} \mathrm{C}$ que podenia promover a formação de alteraçōes pulpares irreversíveis (ZACH e COHEN, 1965). No entanto, KELLER e HIBST (1989) apresentaram os primeiros estudos sobre a utilização de um laser de Érbio: Ítrio-Alumínio-Granada $(\mathrm{l}=2,94 \mathrm{~mm})$ para realizar preparos cavitários. Logo, um grande número de estudos apontaram este tipo de laser como sendo efetivo para ser aplicado em tecidos duros uma vez que atuava pelo princípio de ablação sendo bem absorvido pela água dos tecidos dentánios, colágeno e hidroxiapatita não permitindo o aumento de temperatura acima dos niveis biologicamente seguros.

No entanto com desenvolvimento de materiais adesivos, desde a aplicação do condicionamento ácido sobre o esmalte ${ }^{7}$ e a criaçāo dos compósitos ${ }^{8}$, a Odontologia tomou-se adesiva. Paralelamente a isto, o estabelecimento dos conceitos sobre a remoção de dentina cariada e a determinação da possibilidade de remoção seletiva dos tecidos dentários foram muito importantes. Esta nova tendência de realizar preparos cavitários mais conservadores com a utilizaçāo do laser e a abrasão a ar está hoje sendo denominada de “ Microdentística" 9. Em função disto, estudar a relação do emprego dos métodos para a realização de preparos cavitánios hoje disponiveis-alta rotação, abrasão a ar e laser de Er:YAG - com a técnica adesiva foi o objetivo deste trabalho procurando avaliar a resistência de união à tração de um sistema adesivo à dentina previamente tratada com dos métodos citados.

\section{MATERIAL E MÉTODO}

Trinta e quatro terceiros molares humanos retidos foram extraídos por indicação terapêutica. As raízes foram seccionadas na junção cementoesmalte e a coroa cortada no sentido mésio-distal, obtendo-se duas metades uma vestibular e outra lingual. As porçōes dentárias foram incluídas em resina acrilica autopolimerizável ( JET Clássico) totalizando 45 amostras. Após, a superfície dentária foi desgastada $\mathrm{em} 2 \mathrm{~mm}$ de profundidade com auxílio de um torno mecânico (NARDINI) com $630 \mathrm{rpm}$ sob refrigeração de água destilada e, em seguida, foram utilizadas seqüencialmente lixas d'água de granulação 400 e 600 . As amostras foram armazenadas em água destilada a temperatura ambiente. Quinze superfícies dentinárias foram preparas com uma turbina de alta rotação (KAVO). A peça de mão foi acoplada a uma haste metálica especialmente montada para a realização de um único movimento horizontal. O dente embutido foi estabilizado em uma base metálica acoplada à uma mesa de microscópio ótico. A asperização da superficie foi realizada com uma ponta diamantada KG Sorensen ${ }^{\circ} 3008$ sob refrigeração de spray de ar-água pelo tempo de 5

\footnotetext{
* Resumo de dissertação para obtenção do título de Mestre em Clínicas Odontológicas - Cariologia da FO/UFRGS

** Mestre em Cariologia - FO-UFRGS, Doutorando em Dentística Restauradora - FO-USP

**** Mestre e Doutor em Materiais Dentários - UNICAMP, Professor Adjunto de Dentística Restauradora FO-UFRGS, Coordenador do Curso de Especializaçāo em Dentística Restauradora FO - UFRGS
}

R. Fac. Odontol., Porto Alegre, v. 40, n. I, p. 16-17, set. 1999 
segundos. Em seguida, foram armazenados em água destilada à temperatura ambiente até o momento de confeç̧ão dos corpos para realização do teste de resistência de união à traçāo. Outro grupo de 15 dentes foi tratado com laser de Er:YAG Kavo, KeyLaser (Kavo) com 2,94 mm de comprimento de onda com energia por pulso de $450 \mathrm{~mJ}$ freqüência de $2 \mathrm{Hze} 144,69 \mathrm{~J} / \mathrm{cm}^{2}$. A peça de mão 2051 ficou em modo focado a uma distância aproximada de 12 a $15 \mathrm{~mm}$ pelo tempo de 10 segundos. A seguir, foram armazenados em água destilada. O terceiro grupo de 15 amostras foram tratados com um equipamento de abrasão a ar Mach 5 (Kreativ Inc.) com parâmetros de pressão de 80 psi, partículas de óxido de alumínio de 27,5 $\mathrm{mm}$, fluxo de pó de $5 \mathrm{~g}$ /minuto, ponteira da peça de māo com diâmetro de $0,035 \mathrm{~cm}$ a uma distância aproximada de $1-2 \mathrm{~mm}$ da superfície dentinária. $\mathrm{O}$ tempo de aplicação em cada amostra foi de 10 segundos sendo após armazenados em água destilada.

Para a confecção dos corpos de prova para o teste de resistência de união à tração foi delimitada a área de aplicação do sistema adesivo. Um papel contact com um orifício de $3 \mathrm{~mm}$ de diâmetro foi posicionado sobre a regiāo central da superficie preparada previamente com um dos três métodos. O sistema adesivo Single Bond ( $3 \mathrm{M}$ ) foi aplicado seguindo as orientaçôes do fabricante. Após, foi confeccionado na área delimitada pelo papel contact um cone de resina composta $\mathrm{Z100}(3 \mathrm{M})$ cor A3. Os corpos de prova foram então armazenados em frascos plásticos individualmente em água destilada e mantidos em uma estufa (FANEM) a $37^{\circ} \mathrm{C}$ durante 24 horas. Decorrido o período de armazenagem, os corpos de prova foram submetidos ao teste de resistência de união à tração em uma máquina de ensaio universal EMIC DL2000 . O corpo de prova foi posicionado em uma luva metálica fixada na parte inferior da máquina de ensaio universal sendo um mordente superior adaptado ao cone de resina composta. $O$ teste foi realizado com uma velocidade constante de afastamento do mordente superior correspondente a $0,5 \mathrm{~mm} /$ minuto, até ocorrer a ruptura da união entre o cone de resina composta e a superfície dentinária. Os resultados obtidos em Kgf foram transformados em MPa e submetidos análise estatistica através da ANOVA seguido do teste de Tukey ao nível de significância de $1 \%(p<0,01)$. Após o teste de resistência de união os corpos de prova foram observados com auxílio de um microscópio estereoscópio (Wild-HEERBRUGG, Switzerland) em aumentos de 25 vezes para determinar o tipo de falha. A classificação do tipo de falha foi a seguinte:

- adesiva: rompimento apenas da interface dentina/adesivo

- coesiva em dentina: rompimento da estrutura dentária

- coesiva em resina composta: rompimento desta

- mista: presença de falha adesiva e falha coesiva em dentina e/ eou resina composta.

\section{RESULTADOS}

Os resultados obtidos no teste de resistência de uniāo à tração do sistema adesivo Single Bond à dentina tratada com alta rotação, laser de Er:YAG e abrasāo a ar estão expressos na tabela l e ilustrados na figura 1 .

Tabela l. Comparação entre as médias dos diferentes métodos para execuçāo de preparo cavitánios quando submetidos ao teste de resistência de uniāo à tração do sistema adesivo Single Bond à dentina (MPa) e seus respectivos desvios padróes. Porto Alegre, 1999.

\begin{tabular}{|l|c|c|c|}
\hline $\begin{array}{c}\text { Métodos de } \\
\text { preparos } \\
\text { cavitários }\end{array}$ & $\begin{array}{c}\text { Resistência de } \\
\text { uniāo à tração }\end{array}$ & $\begin{array}{c}\text { Desvio } \\
\text { Padrão }\end{array}$ & $\mathbf{p}$ \\
\hline Alta Rotação & $17,52 \mathrm{~A}$ & 2,01 & 0,01 \\
\hline Laser de Er:YAG & $16,65 \mathrm{~A}$ & 1,5 & \\
\hline Abrasāo a ar & $15,83 \mathrm{~A}$ & 1,5 & \\
\hline
\end{tabular}

*médias seguidas de mesma letra não diferem entre si

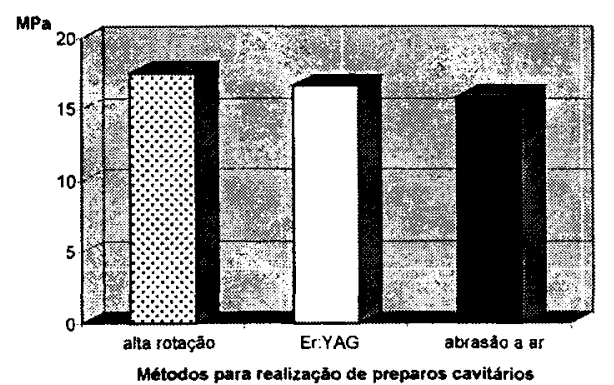

* médias seguidas de mesma letra não diferem entre si.

\section{SUMMARY}

The aim of this study was evaluated, in vitro, the tensile bond strength to dentin of the Single Bond ( $3 \mathrm{M})$ adhesive system applied over dentin surfaces treated with high-speed handpiece, Er:YAG laser or air abrasion. Thity four enclosed molars extracted due to therapeutic indication had been used. The teeth was sectioned on the mesial-distal sense. The dental portions was included in a selfcured acrilic resin and so fourty five samples was randomly divided in three groups. The first group was treated with a diamond bur plus high-speed handpiece (Kavo) for five seconds under water cooling. On the laser group was used the Er:YAG KavoKey laser (Kavo) with energy of $450 \mathrm{~mJ} /$ pulse and $2 \mathrm{~Hz}$ under water cooling. In the air abrasion group was used a Mach 5 (Kreativ) device with 27 $\mathrm{mm}$ alumina oxide particles powder. After the treatments was applied the Single Bond ( $3 \mathrm{M})$ and $\mathrm{Z} 100$ resin composite. The tensile test was realized in a universal testing machine EMIC DL-2000 at cross-head speed of $0,5 \mathrm{~mm} /$ minute. The average results was: high-speed handpiece (17,52 MPa), Er:YAG laser ( 16,65 MPa) and air abrasion $(15,83)$. The results was submitted to statistical treatment by ANOVA and Tukey's test $(p<0,01)$ that showed the differnce between the tested groups was not significant.

\section{KEYWORDS:}

Laser, abrasion, dentin, bond

\section{BIBLIOGRAFIA}

9. CROSS H. RUSSEL. Director of Institute of Food Science and Engineering at Texas. Comunicação pessoal. 1997.

10. FITZGIBBON EJ, BARTZOKAS CA, MARTINMV, et al: the Source Frequency and Extent of Bacterial Contamination of Dental Unit Water Systems.Br. Dent. London. y. v. 157, p.98101, Avg., 1984.

11. GROSS, A; DEVINE, M); CUTRIGHT, DE, Microbial Contamination of Dental Units and Ultrasonic Scalers. Periodontal, 47:670-3, 1976.

12. KAYSER, WV; HICKMAN, KC et al, Bacteriological Evaluation of an Ultra-Pure Water-Distilling System. Appl. Microbial., v.30, p.704-06. 1975.

13. KELLETT, M; HOLBROOK, WP. Bacteria Contamination of Dental Handpieces. J. Dent. Res. v.8, n3, p.249-53, Sept.1980.

14.KELSTRUP J; FUNDER-NIELSON. TD; THEILADE J. Microbial Aggregate Contamination of Water Line in Dental Equipment and its Control. Acta Pathol Microbial. Scand. v.85, (sect. B), p. 177-83, 197 ,

15. MARTIN MV, The Significance of the Bacterial Contamination of Dental Unit Water Systems. Be Dent. J. London, v.163, p.152-4, Sept. 1987.

16. MAYO, JA; OERTLING, KM et al, Bacterial Biofilm: Source of Contamination in Dental Air. Wate Syringes. Clin. Prevent. Dent. v.12, n.2, p. 13-20 Jur/Jul. 1990.

17. McENTEGARTMG, CIARKA: Colonization of Dent Unit by Water Bacteria. Br. Dent. J. London, v. 13i p.40-2, 1974

18. MICHEL R, and BORNEFFM, Significans of Amoeb: and other Protozoa in Water Conduit Systems or Dental Units. Zbl . Bakt. Hyg. B. v.187, p.130$52,1986$.

19. PANKHURST CL, PHILPOTT HOWARD JN, The Microbiological Quality of Water in Dental Chair Units. J. Hosp. Infect. London, v.23, n3, p. 16:74, Mar. 1993.

20. REINTHALER FF and MASCHER F, Legionell Pneumophila in Dental Units. Zbl. Bakt. Hyg. B v. 183, p. $86-8,1986$

21. SCHEID RC, ROSEN S and BECK FM, Reduction $\alpha$ CFUs in High-Speed Handpieces Water Lines Ore Time. Clin. Prev. Dent. v.12, n.2, p.9-12, Jun/Ju? 1990.

22. STANDARD METHODS for the Examination of Wate and Wastewater, 19.ed., 1995.

23. TIPPETT, BF, EDWARDS JL and JENICINSON HE Bacterial Contamination of Dental Water Lines Possible Source of Cross-Infection. N. Z. Dent. I v.84, n378, p.112-113, Oct.1988.

24. WHITEHOUSE RIS, PETERS E et al, Influence ir Biofilm on Micnobial Contamination in Dental Uni: Water. J. Dent. v.19, n.5, p-290-295, Oct, 199!

25. WILLIAMS HN, KELLEY J et al, Assessing microba contamination in clean water dental units an compliance with disinfection protocol. y. Am. Dere Assoc., Chicago, n 9, v.125, p.1205-11, Sept. 199:

26. WILLIAMS JF, JOHNSTON AM et al, Microbi: Contamination in Dental Unit Water Lines. J. Am Dent. Assoc., Chicago, n 10, v.124, p.59-65, O1993. 